\title{
APROVAÇÃO DO "ORÇAMENTO IMPOSITIVO" É INSUFICIENTE PARA DAR CREDIBILIDADE À LEI ORÇAMENTÁRIA
}

Coluna publicada em 10.5.2015:<http://www.conjur.com.br/2015-mar-10/paradoxocorte-aprovacao-orcamento-impositivo-nao-credibilidade-lei-orcamentaria $>$

A recente aprovação pela Câmara dos Deputados da "PEC do Orçamento Impositivo" (Proposta de Emenda Constitucional 358/2013) ${ }^{1}$ torna oportuno voltar ao assunto, sobre o qual já discorri nesta coluna em maio de 2013 (Orçamento impositivo é avanço para a administração), dada a importância que representa para o Direito Financeiro.

Em um ano que começou mal para o Direito Financeiro, como já destaquei recentemente ${ }^{2}$ esta deve ser recebida como uma boa notícia.

Não darei o mesmo enfoque da coluna anterior, para a qual remeto o leitor, pois a efetiva aprovação dessa emenda constitucional permite ampliar as reflexões sobre o tema, agora já à luz do texto aprovado, especialmente para esclarecer alguns pontos polêmicos que surgiram durante esse período de discussões.

A PEC promoveu alterações na redação dos artigos 165, 166 e 198 da Constituição, introduzindo modificações no sistema de execução orçamentária, com a finalidade de tornar obrigatória a realização de parte das despesas previstas na lei orçamentária. Vem integrar o ordenamento jurídico após longa tramitação de várias propostas, destacando-se a PEC 22/2000 do Senado Federal, tendo havido impulso e divulgação em 2013, com o debate sobre a PEC 565/2006 na Câmara dos Deputados.

1 Câmara aprova PEC do orçamento impositivo em 2o turno. Câmara Notícias (<http://www2. camara.leg.br/camaranoticias/noticias $>$ ).

2 Direito Financeiro precisa ser levado a sério, e 2015 começou mal, nesta edição, p. 183-188. 
A lei orçamentária, já reconhecida como a mais importante depois da Constituição, ${ }^{3}$ sempre enfrentou problemas com relação à concretização de seus dispositivos, dadas suas peculiaridades, o que originou aos debates até hoje presentes sobre sua natureza "autorizativa" ou "impositiva".

Como tenho defendido, não é coerente com o ordenamento jurídico vigente, que tem a lei orçamentária contextualizada em um sistema de planejamento governamental, na qual desempenha papel fundamental, considerar as disposiçôes da lei orçamentária meras "autorizações" para as despesas públicas. Acolher tal interpretação é fazer pouco dessa lei tão relevante. Ainda que sejam necessários instrumentos de flexibilidade que permitam adequar as disposiçōes da lei orçamentária às inevitáveis intercorrências que surgem no decorrer do exercício financeiro, há que se reconhecer o caráter mandatório - ou "impositivo" - da lei orçamentária.

Os principais aspectos da nova redação da Constituição estão no art. 165, $\$ \$ 9^{\circ}$ e 11 , ao preverem $1,2 \%$ da receita corrente líquida para as emendas parlamentares individuais ao projeto de lei orçamentária, que se tornam de execução obrigatória, ressalvados apenas impedimentos de ordem técnica, caso em que serão adotadas as medidas especificadas no $\$ 14 .^{4}$

Outro item importante é a destinação de metade desse montante para as açōes e serviços públicos de saúde, criando uma "vinculação" de recursos ao setor. Desde já convém ressalvar que, embora louvável privilegiar área tão fundamental para assegurar o cumprimento de direitos fundamentais como a saúde, as vinculações não são capazes por si só de resolver os problemas, como já destaquei em coluna anterior. $^{5}$

Fato é que todo e qualquer mecanismo que venha a intensificar o caráter impositivo da lei orçamentária é importante para conferir maior seriedade e gerar mais confiança aos agentes públicos e privados quanto às previsóes das açóes

3 Min. Ayres Britto, STF, ADI-MC 4.048-1/DF, j. 14.5.2088, p. 92 dos autos.

4 Art. 166. (...)

$\$ 9^{\circ}$. As emendas individuais ao projeto de lei orçamentária serão aprovadas no limite de $1,2 \%$ (um inteiro e dois décimos por cento) da receita corrente líquida prevista no projeto encaminhado pelo Poder Executivo, sendo que a metade deste percentual será destinada a açóes e serviços públicos de saúde.

$\$ 11$. É obrigatória a execução orçamentária e financeira das programações a que se refere o $\$ 9^{\circ}$ deste artigo, em montante correspondente a 1,2\% (um inteiro e dois décimos por cento) da receita corrente líquida realizada no exercício anterior, conforme os critérios para a execução equitativa da programação definidos na lei complementar prevista no $₫ 9^{\circ}$ do art. 165 .

5 Vinculações orçamentárias não são a panaceia dos problemas, nesta edição, p. 207-210. 
governamentais, tornando, com isso, mais eficiente a gestão pública. Nisso reside a principal virtude dessa alteração constitucional.

Limitar essa obrigatoriedade de cumprimento da lei orçamentária às emendas parlamentares individuais é, no entanto, reduzir demasiadamente o alcance de uma medida que deveria compreender todo o orçamento público - e essa seguramente é a principal crítica a ser registrada.

A redação prevista inicialmente na PEC 22/2000 não continha essa restrição, dispondo que "A programação constante da lei orçamentária anual é de execução obrigatória, salvo se aprovada, pelo Congresso Nacional, solicitação, de iniciativa exclusiva do Presidente da República, para cancelamento ou contingenciamento, total ou parcial, de dotação" (proposta de redação ao art. 165-A da Constituição), ${ }^{6}$ mesma redação que constava da PEC 565/2006.

Tendo em vista a sistemática adotada pelo Congresso Nacional de criar uma "cota" para as emendas parlamentares, tema sobre o qual já se falou nesta coluna, é em função da execução delas que se estabeleceu uma relação conflituosa entre os Poderes Executivo e Legislativo pelo comando da destinação dos recursos orçamentários. Daí porque, durante a tramitação da PEC do Orçamento Impositivo, a redação final do texto acabou por restringir a impositividade do orçamento aos valores que nele se inserem por meio das emendas parlamentares individuais e, com isso, perdeu-se uma excelente oportunidade de aprovar a proposta inicial mais abrangente.

É importante aproveitar a oportunidade do debate acerca do assunto para esclarecer muitas questôes controvertidas e críticas ao orçamento impositivo e à proposta aprovada, o que se pretende fazer a seguir.

1) O orçamento impositivo "engessa" a atuação do governo e compromete a eficiência da administração

Trata-se de argumento que revela fato em parte verdadeiro. No entanto, isso deve ser visto positivamente, como qualidade, e não defeito. Não há dúvida quanto a promover algum grau de "engessamento" na ação governamental, sob o ponto de vista do Poder Executivo, responsável maior pela condução da execução orçamentária. Mas não se pode afirmar que compromete a eficiência da administração pública.

Sendo o orçamento uma lei, aprovada para estabelecer a destinação dos gastos durante todo o exercício financeiro, o que se espera é seu fiel cumprimento, de

6 Diário do Senado Federal, 7 de junho de 2000, p. 11.983.

7 Emendas ao orçamento e o desequilíbrio de Poderes, nesta edição, p. 219-222. 
modo que, no final do exercício, o que nele está previsto seja efetivamente executado. Reduzir a flexibilidade e diminuir a discricionariedade do Poder Executivo na execução orçamentária ("engessando-o") são medidas adequadas para atingir esse objetivo, que dão maior previsibilidade, credibilidade e transparência à lei orçamentária, além de segurança jurídica à administração pública e a toda a sociedade.

A flexibilidade é inerente ao processo de execução orçamentária, mas deve orientar-se para cumprir o estabelecido na lei orçamentária em seu aspecto essencial, limitando-se a proceder aos ajustes que se façam imprescindíveis para adaptar o orçamento às imprevisibilidades surgidas no decorrer do exercício financeiro.

Não se pode concluir que exigir o cumprimento de uma lei tal como aprovada seja motivo de ineficiência administrativa, pelo contrário. A segurança jurídica e a credibilidade conferida à lei, nessa hipótese, são razões para tornar mais eficiente a administração pública.

2) As emendas parlamentares atendem apenas a interesses paroquiais, desorganizam o planejamento e o orçamento, prejudicam a gestão e comprometem as políticas públicas

A redução da participação parlamentar na elaboração do orçamento às emendas parlamentares, com o sistema de "cotas" já institucionalizado, já é por si só uma grave distorção no processo orçamentário, que mitiga a importância da participação do Congresso Nacional na elaboração do orçamento federal.

Deixa-o de lado na discussão sobre a definição da alocação de recursos orçamentários para as principais políticas públicas, limitando sua participação à inserção de despesas que pouco representam, se considerado o orçamento como um todo, ainda que envolvam altas somas de dinheiro público.

Isso deturpa a atuação parlamentar, que volta suas preocupações para atender a demandas locais e específicas de setores e grupos, os chamados interesses "paroquiais", o que tem sido duramente criticado, e não sem razão.

Algumas vezes até exageradamente, como se vê da opinião expressa pelo jornalista Fernando Rodrigues, que considerou a obrigatoriedade da execução financeira das emendas parlamentares um "desastre gerencial", prevendo que os candidatos ao Congresso Nacional, nas campanhas eleitorais, "poderão zanzar pelas ruas com uma plaquinha pendurada no pescoço: valor: 14 milhôes". ${ }^{8}$ Em sentido semelhante escreveu Raul Velloso, que via a PEC como uma "manobra", verdadeira "brincadeira de mau gosto" que "garantiria uma fatia de R\$10 milhôes da pizza

8 Desastre no manejo político. Folha de S.Paulo, 9 de novembro de 2013, p. A2. 
orçamentária para cada parlamentar patrocinar algum gasto junto à sua base de apoio"?

Como mencionado, restringir a obrigatoriedade da execução orçamentária às emendas parlamentares individuais está longe do ideal, pois o que se espera e deseja, para dar seriedade à lei orçamentária, é que o orçamento seja cumprido tal como aprovado, e não somente no que tange às referidas emendas.

Cumpre ressaltar que as emendas parlamentares só podem ser aprovadas se compatíveis com o plano plurianual e a lei de diretrizes orçamentárias (CF, art. $\left.166, \$ 3^{\circ}, \mathrm{I}\right)$, e, até por representarem pequena parcela do orçamento público, não há como desorganizarem o sistema de planejamento e orçamento, nem comprometerem a gestão, a implementação e a execução das políticas públicas.

Evidentemente há que se exigir atuação mais responsável do Congresso Nacional ao usar as emendas para atender o interesse público. Isso, no entanto, não pode comprometer a seriedade da lei orçamentária, nem a obrigatoriedade do cumprimento do que nela foi aprovado, o que é fundamental para dar segurança ao ordenamento jurídico. Nem justificar a transferência do poder de decidir sobre os gastos públicos para o Poder Executivo, como se este fosse mais responsável e competente para melhor alocá-los.

\section{3) A PEC do Orçamento Impositivo é um casuísmo}

De fato, há de se reconhecer que esta PEC, nas circunstâncias em que foi aprovada, e restrita à obrigatoriedade na execução das emendas parlamentares, evidencia uma ação oportunista do Congresso Nacional, que permite entrever o interesse em tão somente priorizar o atendimento das destinaçôes de recursos orçamentários patrocinados pelos parlamentares.

A questão foi exposta com muita propriedade por José Marcos Domingues recentemente, ${ }^{10}$ que deixou evidente a inadequação em se privilegiar emendas individuais dos congressistas em detrimento das políticas públicas que devem ser planejadas, refletidas e discutidas em função do bem comum.

Conforme já exposto anteriormente, é evidente que seria muito melhor a aprovação da PEC original que estendia a obrigatoriedade da execução da lei orçamentária como um todo; no entanto, pior é não haver qualquer obrigatoriedade na execução do orçamento, dando margem à interpretação de que se trata de lei

9 Proposta inoportuna. Folha de S.Paulo, 10 de agosto de 2013, p. A3.

10 Pelo controle judicial do orçamento impositivo de emendas individuais, publicada em 19 de fevereiro de 2015, no ConJur. 
meramente autorizativa dos gastos, cuja execução se sujeita à ampla discricionariedade do Poder Executivo.

O orçamento impositivo vem valorizar a lei orçamentária, tem por finalidade conferir maior efetividade a seus dispositivos e, razão pela qual, devem ser apoiadas as açôes no sentido de implementá-lo.

Por isso, é melhor olhar a restrição às emendas parlamentares não como uma medida casuística, que de fato aparenta ser, mas sim como uma medida excessivamente tímida para o que se espera, que é tornar a lei orçamentária uma norma de eficácia plena e de elevada credibilidade.

A PEC aprovada infelizmente não foi abrangente o bastante para fazer com o que o orçamento deixe de ser uma peça de ficção, como desejou a Senadora Ana Amélia ao tratar do tema. ${ }^{11}$

Mas a nova redação dada à Constituição é um começo. Insuficiente para dar à lei orçamentária a credibilidade e segurança jurídica que se espera da lei mais importante depois da Constituição.

É necessário avançar ainda muito mais.

11 O fim da ficção. Folha de S.Paulo, 10 de março de 2013. 